\title{
Respiratory distress syndrome and inositol supplementation in preterm infants
}

\author{
M HALLMAN, A-L JÄRVENPÄÄ, AND M POHJAVUORI \\ Children's Hospital, University of Helsinki, Helsinki, Finland
}

SUMMARY We report a randomised double blind trial of myo-inositol (inositol) supplementation for 10 days in 74 preterm infants with a birth weight less than $2000 \mathrm{~g}$ (mean gestational age 29.5 weeks and mean birth weight $1266 \mathrm{~g}$ ). All infants required artificial ventilation for treatment of respiratory distress syndrome. Inositol $(120-160 \mathrm{mg} / \mathrm{kg} /$ day $)$ was administered by the ingastric or intravenous route. The 37 infants who received inositol supplementation required less mechanical ventilation during days $4-10$, had less failures of indomethacin to close ductus arteriosus, and had less deaths or bronchopulmonary dysplasia, or both, than the infants treated with placebo. There were no detectable adverse effects. These preliminary results suggest that inositol is an important nutrient in immature preterm infants.

Myo-inositol (inositol), a six carbon sugar alcohol, is at least as abundant as glucose in the body. In adults virtually all inositol is intracellular, whereas fetuses and immature preterm infants may also have high concentrations of inositol in serum. ${ }^{1-3}$ Inositol is a precursor of phosphoinositides. These phospholipids are membrane components and may serve, for instance, as a putative neurotransmitter, as 'tertiary' messengers of several hormones, and as a growth factor. ${ }^{4}$ Although rodents on an inositol deficient diet may develop skin, ${ }^{5}$ gastrointestinal, ${ }^{6}$ and hepatic ${ }^{7}$ disturbances, dietary inositol requirements have not been established. ${ }^{8}$ The observation that inositol is synthesised in any tissue and is taken up into intracellular space by active transport has led to a limited nutritional interest in this compound.

Recently, it was found that an excess of inositol potentiates the glucocorticoid induced acceleration of the differentiation of lung surfactant. ${ }^{9}$ As critically ill newborn are deprived of breast milk rich in inositol, resulting in a decrease in serum inositol, ${ }^{3-10}$ it was prudent to test whether exogenous inositol influenced the respiratory course in severe respiratory distress syndrome (RDS). The rationale of the study was to provide an intake of inositol similar to that in full breast feedings. The present report deals with a randomised double blind pilot study that evaluates the influence of inositol in treatment of RDS.

\section{Patients and methods}

Clinical methods.

Study population

The study was conducted in our hospital between January 1983 and August 1985. Preterm infants had to fulfil the following criteria to be included in the study:

(1) Birth weight $<2000 \mathrm{~g}$.

(2) Diagnosis of RDS.

(3) Mechanical ventilation required for a period of at least 24-48 hours.

(4) No other cardiopulmonary disease, malformation, or sepsis at birth or fetal hydrops.

RDS was diagnosed on the basis of the following criteria:

(1) Symptoms and findings of respiratory distress (tachypnoea, retractions, grunting, apnoea, or extra oxygen required) for at least 72 hours from birth.

(2) Chest $x$ ray film compatible with RDS. ${ }^{11}$

(3) Low lecithin:sphingomyelin ratio and undetectable phosphatidylglycerol in tracheal aspirate during the first 24 hours.

The lung effluent was obtained shortly after intubation during routine suctioning of the airways. Normal saline (1-2 ml) was injected through the endotracheal tube. After a short hand ventilation any fluid that was recovered during suctioning of the 
airways $(1 \mathrm{~cm}$ distal to the tip of the endotracheal tube) was collected into a Leuken's trap. The phospholipids were analysed using two dimensional thin layer chromatography. ${ }^{12}$

\section{Administration of sugars}

Infants were randomly and blindly assigned to be treated with inositol or placebo (glucose) after their parents had consented to their participation. Each set of solutions, containing either inositol or glucose ( $5 \%$ weight/volume each) had a code number. Only the pharmacist preparing the doses knew the contents of the drug packages. The sugars were given intragastrically shortly before gavage feedings in a dose of $160 \mathrm{mg} / \mathrm{kg} /$ day, divided into four doses. When all oral feeds were withheld the sugars were given intravenously. Based on a study of bioavailability (manuscript in preparation) the intravenous dose given was $75 \%$ of the intragastric one. All sugars were stored at $-20^{\circ} \mathrm{C}$ and were discarded with 24 hours of use. The sugars were started at 12-48 hours of age and continued until 10 days. Contraindications for entry into the trial and indications for stopping the administration of sugars were low urine output $(<1 \mathrm{ml} / \mathrm{kg} / \mathrm{h})$ or raised blood urea concentrations $(>8.3 \mathrm{mmol} / \mathrm{l}(50 \mathrm{mg} / 100 \mathrm{ml}))$, or both.

\section{General management of infants}

The indications for intubation and ventilation were apnoea at birth that did not respond to mask ventilation, requirement of $>60 \%$ oxygen, or failure to maintain arterial carbon dioxide tension below $70 \mathrm{~mm} \mathrm{Hg}$. Assisted ventilation was provided by a Baby Bird infant ventilator, using intermittent mandatory ventilation or continuous positive airway pressure. In general initial ventilator rates were $20-40 / \mathrm{min}$, inspiratory time $0 \cdot 8-1 \cdot 0$ seconds, peak inspiratory pressure $15-20 \mathrm{~cm} \mathrm{H}_{2} \mathrm{O}$, and positive end expiratory pressure $2-5 \mathrm{~cm} \mathrm{H}_{2} \mathrm{O}$. Peak inspiratory pressure was increased when fractional inspiratory oxygen requirements were higher than 0.8 . Occasionally, when the conventional technique failed, infants were ventilated at a rate of $50-70 / \mathrm{min}$. When the fractional inspiratory oxygen required was below $\mathbf{0} \cdot \mathbf{8}$, peak inspiratory pressure and ventilator rate were decreased. Small preterm infants were extubated when they required fractional inspiratory oxygen $<0 \cdot 3$, positive end expiratory pressure $<3$ cm $\mathrm{H}_{2} \mathrm{O}$, and ventilator rates $<4 / \mathrm{min}$, whereas infants weighing $>1500 \mathrm{~g}$ were given continuous positive airway pressure before extubation. Apnoea of prematurity was treated with theophylline.

All infants had transcutaneous oxygen monitoring when fractional inspiratory oxygen was $>0 \cdot 3$. Arterial oxygen tension was monitored from the abdominal aorta or radial artery. The ventilator settings and oxygen concentrations were adjusted frequently to maintain an oxygen tension or transcutaneous oxygen tension between 50 and $70 \mathrm{~mm}$ $\mathrm{Hg}$ and carbon dioxide tension between 40 and 60 $\mathrm{mm} \mathrm{Hg}$. Blood pressure was measured by Doppler ultrasound method. Infusions of $4 \%$ albumin or fresh frozen plasma $(10-20 \mathrm{ml} / \mathrm{kg})$ and dopamine (initial dose of $2-5 \mu \mathrm{g} / \mathrm{kg} / \mathrm{min}$ ) were given if the systolic blood pressure was below $45-50 \mathrm{~mm} \mathrm{Hg}$.

Patent ductus arteriosus was suspected if there was an enlarged cardiac silhouette and pulmonary vascular plethora on the chest $x$ ray film, increase in pulse pressure, increase in retention of carbon dioxide, or metabolic acidosis, even in the absence of a heart murmur. Patent ductus arteriosus was confirmed by echocardiography. Intravenous indomethacin was given $(0.2 \mathrm{mg} / \mathrm{kg}$ as an initial dose and then $0.1 \mathrm{mg} / \mathrm{kg}$ at 12 and 24 hours) in the absence of contraindications (low platelets or active bleeding). If closure was not evident within 48-72 hours as assessed by sequential echocardiography the patent ductus arteriosus was surgically ligated.

Mean airway pressure, when not directly measured at the proximal airway using a Peumogard (Novametrix Medical Systems, Wallingford, Connecticut, United States) was calculated using a previously published formula. ${ }^{13}$ Regression analysis between the measured $(x)$ and the calculated $(y)$ values showed a good linear correlation $(r=0.92$, regression coefficient $=1.05$, intercept $=0.3 \mathrm{~cm}$ $\mathrm{H}_{2} \mathrm{O}$ ). So called ventilatory index (mean airway pressure $\times$ fractional inspiratory oxygen/oxygen tension) and the arterial:alveolar oxygen ratio (a/A $\mathrm{PO}_{2}$ ) were calculated as previously described. ${ }^{14}$ The requirements for fractional inspiratory oxygen a/A $\mathrm{PO}_{2}$ ratio, mean airway pressure, ventilatory index, peak inspiratory pressure, positive end expiratory pressure, ventilator rate, and blood gases were recorded at 1 (SD 0.5), 12 (SD 2), and 24 (SD 2) hours and thereafter at intervals of 24 hours until the age of 10 days.

The clinical diagnosis of bronchopulmonary dysplasia was made on the basis of two criteria.

(1) Respiratory distress and supplemental oxygen required for longer than 28 days.

(2) Persistent strands of densities in both lungs, alternating with areas of normal or increased lucency, or Northway radiographic stage 3-4. ${ }^{15}$

Cranial ultrasound scans were obtained serially, and intracranial haemorrhages were classified using the grading scale of Papile et al. ${ }^{16}$ Necrotising enterocolitis was diagnosed on the basis of clinical manifestations: abdominal $x$ ray showing pneumatosis intestinalis and air in the portal circulation. The diagnosis of retrolental fibroplasia was based on 
ophthalmological examination at postconceptional ages of 9 and 13 months.

Statistical evaluation. Biomedical Computer Program (BMPD statistical software, University of California Press, Berkeley, California, United States) was used for statistical calculations.

As this was the first study to evaluate the effect of inositol in the newborn and the animal studies were not relevant in terms of estimating the magnitude of any effect we elected at the beginning of the trial to examine the data when between 25 and 28 new patients were enrolled, to test whether continuing the study was justified. The present report represents the third interim analysis.

According to experimental data inositol accelerates synthesis of surfactant in the immature lung. It was therefore prudent to adopt outcome criteria that were similar to those used in surfactant substitution trials. Accordingly, the major outcome was categorised in two groups: (1) 'Intact' survival-that is, survival without bronchopulmonary dysplasia; (2) death or bronchopulmonary dysplasia, or both. According to analysis of our results during the years 1980-82 the occurrence of 'intact' survival was 50\% in ventilated infants with RDS and birth weight less than $2000 \mathrm{~g}$. We chose to limit the total number of infants to a maximum of 150 - that is, enough to detect a $36 \%$ decline in the undesired outcome, assuming a type 1 error of $5 \%$ and a type 2 error of $10 \% .{ }^{17}$

Outcome is affected by a number of prenatal and neonatal variables, and the treatment and control groups could have been accidentally unequal in terms of major prognostic variables. We therefore examined 63 prenatal and neonatal variables obtained from the medical charts. Multiple regression analysis was used to test whether some of the variables that tended to be different between the two groups actually affected the major outcome (BMDP 1R).

The initial severity of illness might have influenced the response to therapeutic intervention. We therefore adjusted for differences in severity in the groups treated with inositol or placebo using analysis of covariance (BMPD IV). Fractional inspiratory oxygen and mean airway pressure before treatment with the sugars was begun at 12 hours were chosen as the respective covariates. This model assumed that the chosen pretreatment variable was related to the treatment response and that the variables concerned were normally distributed. The method of covariance analysis should reduce the estimate of experimental error and thus offer a more precise comparison between the two treatments. The skewness of the variables in each age group sampled was not different from those in a normal distribution. If inositol was indeed effective in decreasing the severity of RDS by means of increasing synthesis of surfactant the effect would probably be evident more than 48 hours after beginning treatment. ${ }^{18}$ Pretreatment values at the age of 12 hours were related, therefore, to fractional inspiratory oxygen and mean airway pressures on days 4-8. In addition, possible differences between the groups treated with inositol and placebo were evaluated using analysis of variance (BMDP 4V) unpaired Student's $t$ test, with or without equality of variances. Equality of

Table 1 Prenatal characteristics of the two treatment groups

\begin{tabular}{lcc}
\hline & \multicolumn{2}{c}{ Treatment group } \\
\cline { 2 - 3 } & Inositol & Placebo \\
\hline Single parent & 2 & 8 \\
Bleeding & 8 & 13 \\
Pre-eclampsia & 13 & 13 \\
Essential hypertension & 2 & 0 \\
Asphyxia & 28 & 22 \\
Tocolytic beta agonist & 23 & 20 \\
Mother on steroids & 1 & 4 \\
Caesarean section & 27 & 23 \\
Maternal smoking & 6 & 9 \\
\hline
\end{tabular}

Table 2 Infant characteristics in the two treatment groups

\begin{tabular}{|c|c|c|}
\hline & \multicolumn{2}{|c|}{ Treatment group } \\
\hline & Inositol & Placebo \\
\hline \multicolumn{3}{|l|}{ Birth weight: } \\
\hline Mean (SD) & $1276(321)$ & $1256(387)$ \\
\hline Range & $600-1860$ & $600-1940$ \\
\hline No $>1500 \mathrm{~g}$ & 9 & 10 \\
\hline No $<10000 \mathrm{~g}$ & 8 & 11 \\
\hline \multicolumn{3}{|l|}{ Gestational age (weeks): } \\
\hline Mean (SD) & $29 \cdot 5(2 \cdot 0)$ & $29 \cdot 5(2 \cdot 1)$ \\
\hline Range & $25 \cdot 4-33 \cdot 0$ & $25 \cdot 0-33 \cdot 4$ \\
\hline No $>31 \cdot 0$ weeks & 9 & 10 \\
\hline No $<28.0$ weeks & 12 & 12 \\
\hline \multicolumn{3}{|l|}{ Small for gestational } \\
\hline age (<10th centile) & 2 & 6 \\
\hline Singletons & 31 & 32 \\
\hline Twins & 6 & 4 \\
\hline Triplets & 0 & 1 \\
\hline $\operatorname{Sex}(M / F)$ & $20 / 17$ & $18 / 19$ \\
\hline \multicolumn{3}{|l|}{ Apgar score at one minute: } \\
\hline$\leqslant 3$ & 12 & 14 \\
\hline $4-6$ & 15 & 12 \\
\hline$\geqslant 7$ & 10 & 11 \\
\hline \multicolumn{3}{|l|}{ Apgar score at five minutes: } \\
\hline$\leqslant 3$ & 2 & 3 \\
\hline $4-6$ & 11 & 9 \\
\hline$\geqslant 7$ & 24 & 23 \\
\hline \multicolumn{3}{|l|}{ Intubated and ventilated } \\
\hline \\
\hline $\begin{array}{l}\text { Mean (SD) first systolic } \\
\text { blood pressure ( } m m H g \text { ) }\end{array}$ & $49(9)$ & $54(10)$ \\
\hline \multicolumn{3}{|l|}{ First tracheal aspirate: } \\
\hline $\begin{array}{l}\text { Mean (SD) lecithin: } \\
\text { sphingomyelin ratio }\end{array}$ & $1 \cdot 1(0 \cdot 4)$ & $1.0(0 \cdot 3)$ \\
\hline Phosphatidylglycerol & 0 & 0 \\
\hline
\end{tabular}


variances was tested using Levene's test. Finally, the proportion of infants in each group with various morbidities or deaths was compared using the $\chi^{2}$ test or Fisher's exact test.

\section{Results}

Of the 83 infants who entered the trial, nine did not fulfil the entrance criteria and were excluded from final analysis. Three had a high lecithin:sphingomyelin ratio and detectable phosphatidylglycerol in tracheal aspirate at birth. Two of these three infants (one in the inositol and one in the placebo group) improved immediately when the mechanical ventilation was decreased and the other (in the placebo group) improved after closure of the ductus arteriosus. Two infants (in the inositol group) had RDS on the basis of the tracheal phospholipid analysis but did not qualify because the duration of their respiratory distress was too short. Two infants (one from each group) died of respiratory failure before the beginning of supplementation. One infant (in the inositol group) had congenital heart disease and another (in the control group) had group B streptococcal sepsis and subsequently died.

Thus 74 infants fulfilled the study criteria, and 37 were assigned to the inositol group and 37 to the placebo group. To ascertain that the two randomised groups did not differ from each other, 35 prenatal variables describing maternal characteristics and obstetric management were compared. No significant differences were apparent (Table 1).

A further 28 neonatal variables describing the condition and treatment in the infants before the beginning of treatment with inositol or placebo were evaluated, and again there were no significant differences (Table 2).

The two groups did not differ from each other in respect of fractional inspiratory oxygen, blood gases, or ventilatory measurements during the first 48 hours. Between days 4 and 10 , however, the infants treated with inositol tended to have a milder respiratory course than the control infants. The infants treated with inositol tended to require less fractional inspiratory oxygen, although the difference was not significant. The a/A $\mathrm{PO}_{2}$ ratio tended to be higher in infants treated with inositol than in control infants (Fig. 1). Between days 4 and 8 the mean airway pressure was lower in infants in the inositol group than in the control group (BMDP IV, $\mathrm{p}<0.05 ; \mathrm{BMDP} 4 \mathrm{~V}, \mathrm{p}<0.01)$. The ventilatory index tended to be significantly lower among the infants treated with inositol between days 4 and 7 (Fig. 2). In addition, during days 8 to 10 , fewer infants in the inositol group required mechanical ventilation than in the control group $(p<0 \cdot 05)$.

To analyse these differences further, the arterial blood gases and respirator settings were compared. Only the ventilator rates tended to be different (Fig. 3). Infants in the inositol group required slower rates than the control infants during days 5 to $7(\mathrm{p}<0 \cdot 02)$.

Fewer infants treated with inositol died or developed bronchopulmonary dysplasia compared with control infants (Table 3). The inositol group also had a tendency towards a lower incidence of pneumothorax and failure of indomethacin induced closure of patent ductus arteriosus. There was no detectable difference, however, in the incidence of intraventricular haemorrhage. Most of the babies

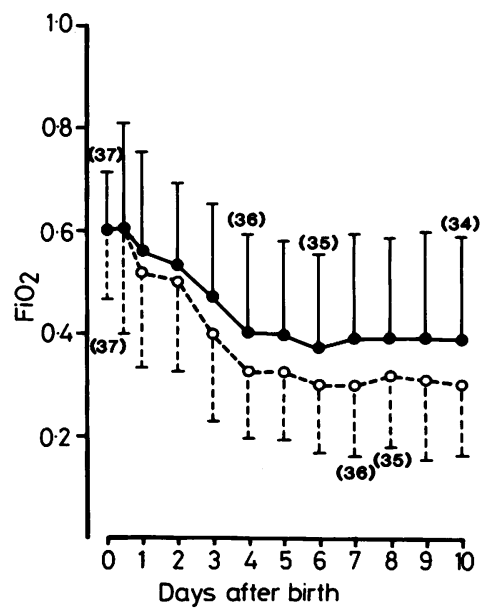

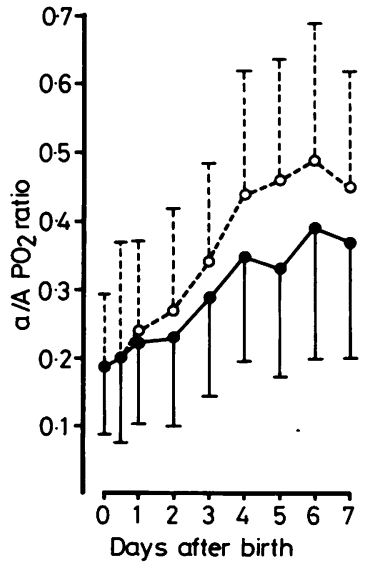

Fig. 1 Fractional inspiratory oxygen $\left(\mathrm{FiO}_{2}\right)$ requirements and arterial-alveolar oxygen tension ratios $\left(\mathrm{a} / \mathrm{A}_{\mathrm{PO}}\right)$ in the two study groups. $\mathrm{O}=$ Mean $(S D)$ values for the inositol group; $=$ mean $(S D)$ values for the control group. Numbers in parentheses indicate number of infants and decrease because of death. The a/ $\mathrm{A} \mathrm{PO}_{2}$ is not shown beyond the first week because measurements of oxygen tension were not always available. 

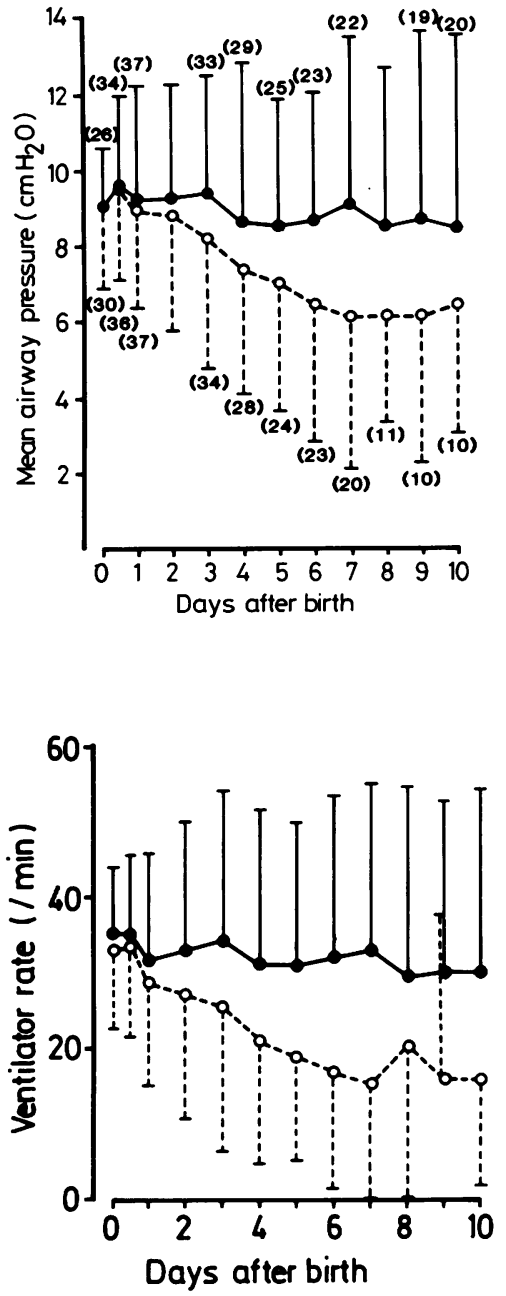

Fig. 3 Mean (SD) ventilator rate among infants in the inositol (O) and control (O) groups.

died from RDS or bronchopulmonary dysplasia (Table 4). Of the surviving infants with bronchopulmonary dysplasia, six required supplemental oxygen between 1 and 2 months (two in the inositol and four in the placebo group), five between 2 and 6 months (one in the inositol and four in the placebo group), and two more than 6 months (one in each group). Nine of the surviving infants with bronchopulmonary required mechanical ventilation after the neonatal period. All surviving infants are being followed up.

To assess whether the differences in the outcome were due to treatment with inositol rather than to
Fig. 2 Mean airway pressure and ventilatory index (mean airway pressure $\times$ (fractional inspiratory oxygen/oxygen tension)) among the ventilated infants. $\mathrm{O}=$ Mean $(S D)$ values for the inositol group; $=$ mean $(S D)$ values for the control group. Numbers in parentheses indicate number of ventilated infants in each group. During days 8-10 significantly fewer infants in the inositol group than in the placebo group required mechanical ventilation $(p<0.05)$. Ventilatory index is not shown beyond the first week because measurements of oxygen tension were not always available.

Conversion: traditional to SI units-Ventilatory index: $1 \mathrm{~mm} \mathrm{Hg}=0.076 \mathrm{kPa}$.
Table 3 Morbidity and mortality in the two treatment groups

\begin{tabular}{|c|c|c|c|}
\hline & \multicolumn{2}{|c|}{ Treatment group } & \multirow[t]{2}{*}{ p Value } \\
\hline & Inositol & Placebo & \\
\hline Deaths* & 5 & 10 & \\
\hline Bronchopulmonary dysplasia & 5 & 11 & \\
\hline $\begin{array}{l}\text { Death or bronchopulmonary } \\
\text { dysplasia, or both }\end{array}$ & & & \\
\hline Pneumothorax & $\begin{array}{l}9 \\
5\end{array}$ & 11 & $<0 \cdot 1$ \\
\hline Pulmonary interstitial emphysema & 5 & 10 & \\
\hline Patent ductus arteriosus & 27 & 27 & \\
\hline \multicolumn{4}{|l|}{ Treatment of patent ductus arteriosus: } \\
\hline None & 6 & 4 & \\
\hline Indomethacin & 21 & 23 & \\
\hline Indomethacin+ligation & 5 & 10 & \\
\hline Indomethacin failure & 5 & 12 & $<0.05$ \\
\hline Necrotising enterocolitis & 1 & 2 & \\
\hline Retrolental fibroplasia & 1 & 4 & \\
\hline \multicolumn{4}{|l|}{ Infections: } \\
\hline $0-7$ days & 2 & 2 & \\
\hline 8-28 days & 5 & 9 & \\
\hline \multicolumn{4}{|l|}{ Intraventricular haemorrhage: } \\
\hline None & 23 & 23 & \\
\hline I or II & 12 & 9 & \\
\hline III or IV & 2 & 5 & \\
\hline
\end{tabular}

*All infant deaths that were related to neonatal condition were included. There was additionally one case of sudden infant death syndrome in the placebo group.

confounding factors, multiple linear regression analyses were performed to assess the influence of some prenatal factors (gestational age, small for gestational age, single parent, bleeding, and mother on steroids) on the outcome. Only gestational age ed significantly $(p=0.05)$ with poor outcome (death or bronchopulmonary dysplasia, or both $=0$; good outcome $=1$ ). Figure 4 shows outcome according to gestational age. 
Table 4 Causes of death and related data in the two treatment groups

\begin{tabular}{|c|c|c|c|c|}
\hline $\begin{array}{l}\text { Case } \\
\text { No }\end{array}$ & $\begin{array}{l}\text { Birth } \\
\text { weight }(g)\end{array}$ & $\begin{array}{l}\text { Gestational } \\
\text { age (weeks) }\end{array}$ & $\begin{array}{l}\text { Age at } \\
\text { death (days) }\end{array}$ & Autopsy findings related to death* \\
\hline \multicolumn{5}{|c|}{ Inositol group } \\
\hline 1 & 600 & $26 \cdot 9$ & 7 & $\begin{array}{l}\text { Massive intracerebral haemorrhage, hyaline membrane disease } \\
\text { (stopping of ventilatory support) }\end{array}$ \\
\hline 2 & 890 & $27 \cdot 0$ & 210 & Bronchopulmonary dysplasia, cor pulmonale \\
\hline 3 & 1245 & $29 \cdot 6$ & 16 & $\begin{array}{l}\text { Necrotising enterocolitis, hyaline membrane disease, } \\
\text { cerebral necrosis and infarcts (birth asphyxia) }\end{array}$ \\
\hline 4 & 1860 & $30 \cdot 6$ & 8 & $\begin{array}{l}\text { Total cerebral necrosis, respiratory distress syndrome, } \\
\text { pneumonia (birth asphyxia) }\end{array}$ \\
\hline 5 & 1380 & $31 \cdot 7$ & 16 & $\begin{array}{l}\text { Severe respiratory distress syndrome, necrosis corticalis renis } \\
\text { (birth asphyxia) }\end{array}$ \\
\hline \multicolumn{5}{|r|}{ 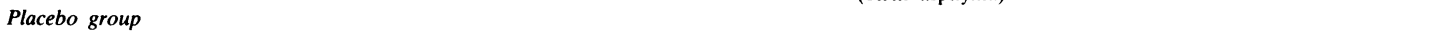 } \\
\hline 1 & 1200 & $27 \cdot 0$ & 14 & Severe respiratory distress syndrome, interstitial emphysema \\
\hline 2 & 850 & $27 \cdot 0$ & 225 & Bronchopulmonary dysplasia, tracheal perforation, pneumothorax \\
\hline 3 & 920 & $25 \cdot 8$ & 5 & Sepsis, hyaline membrane disease, intracerebral haemorrhage \\
\hline 4 & 615 & $28 \cdot 6$ & 15 & Hyaline membrane disease, cerebral infarct, renal cortical necrosis \\
\hline 5 & 1760 & $31 \cdot 1$ & 4 & $\begin{array}{l}\text { Respiratory distress syndrome, intraventricular haemorrhage, } \\
\text { renal cortical necrosis (birth asphyxia) }\end{array}$ \\
\hline 6 & 970 & $26 \cdot 7$ & 23 & $\begin{array}{l}\text { Candidiasis, hyaline membrane disease, intraventricular } \\
\text { haemorrhage }\end{array}$ \\
\hline 7 & 1080 & $29 \cdot 7$ & 28 & $\begin{array}{l}\text { Obstructive tracheobronchitis. } \\
\text { superior vena cava thrombosis }\end{array}$ \\
\hline 8 & 1320 & $30 \cdot 7$ & 13 & $\begin{array}{l}\text { Respiratory distress syndrome. renal failure, intracerebral } \\
\text { haemorrhage }\end{array}$ \\
\hline 9 & 600 & $27 \cdot 4$ & 36 & Bronchopulmonary dysplasia \\
\hline 10 & 1410 & $31 \cdot 0$ & 10 & $\begin{array}{l}\text { Massive intracerebral haemorrhage, respiratory distress syndrome } \\
\text { (stopping of ventilatory support) }\end{array}$ \\
\hline
\end{tabular}

${ }^{*}$ Following cases had histological grade 3 bronchopulmonary dysplasia on autopsy: inositol: 3 and 5, placebo: 1,4 , and 7 .

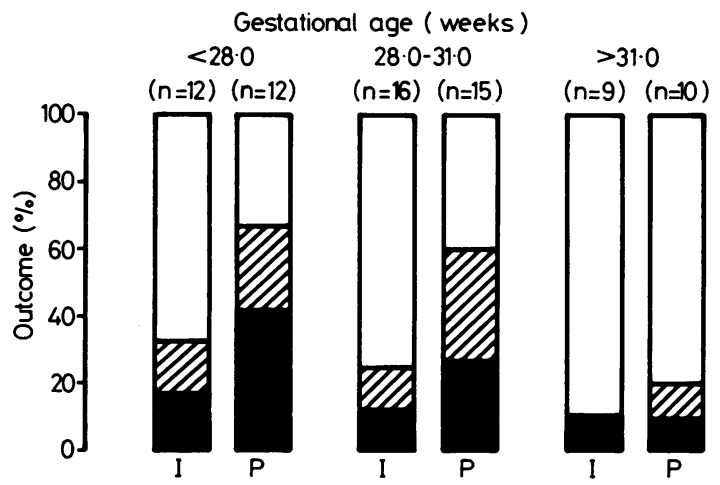

Fig. 4 Outcome of infants according to gestational age. $I=$ grouptreated with inositol; $P=$ group treated with placebo. Black areas represent deaths; hatched areas represent infants with bronchopulmonary dysplasia.

\section{Discussion}

This randomised double blind trial involving preterm infants with RDS provides the first evidence that supplementation with inositol decreases the ventilatory needs and moderates the course of respiratory failure. In addition, there were fewer deaths or cases of bronchopulmonary dysplasia among the infants treated with inositol. The result may seem surprising because inositol had no im- mediate effects on ventilatory requirements or blood gases. In contrast, effective treatments of respiratory failure have had a direct, immediate effect on lung function, thus reversing the progressive course of respiratory failure, decreasing the incidence of severe complications, and reducing the number of infants who eventually developed bronchopulmonary dysplasia. Despite this, no infant with RDS died within 48 hours after beginning treatment with the sugar, and only two died before the sugar was given. The respiratory support was effective enough in most cases, therefore, to allow sufficient time (about 48 hours) ${ }^{9}$ for the effect of inositol to take place, and the study covered more than $90 \%$ of the population with RDS. The birthweight limit of less than $2000 \mathrm{~g}$ was chosen because the prognosis of RDS in this weight group is still poor, and oral feedings are often withheld.

Although inositol prevents the synthesis of the second major surfactant component, phosphatidylglycerol, the paucity of this phospholipid in RDS is not a cause but a consequence of lung immaturity.$^{1920}$ According to current theory, inositol (inositol-phosphoinositide pair) augments the effect of glucocorticoid and thyroid hormone in the synthesis of surfactant phosphatidylcholine. ${ }^{9}$ Phosphatidylglycerol may have a similar function. ${ }^{921}$ The synthesis of phosphatidylglycerol in the immature lung is inactive, however, regardless of extracellular inositol concentration (Hallman M. Un- 
published observations.), whereas inositol is easily available for synthesis of surfactant phosphatidylinositol in immature alveolar cells, provided that the serum inositol concentration is high. ${ }^{21} 22{ }^{2}{ }^{10}$ Mandatory withholding of the breast milk feedings from sick preterm infants decreased serum inositol concentrations sometimes below those present in the immature fetus, ${ }^{10}$ and low serum inositol concentrations in small preterm infants suffering from RDS were not associated with a favourable prognosis either. ${ }^{3}$ The aim of the present study, therefore, was to 'normalise' the intake of inositol and to find out whether inositol affects the natural history of RDS.

Studies with somewhat similar objectives but with different drugs have been conducted before. Administration of cortisol to newborn infants with RDS did not affect the course of the disease. ${ }^{23}$ One possible explanation for the lack of effect of glucocorticoids is the increase in serum cortisol concentration in RDS. ${ }^{23}$ Also adverse effects of glucocorticoids possibly mask the beneficial ones or the time required for the beneficial effect of glucocorticoids was possibly too long. ${ }^{18}$ Exogenous natural surfactant given in RDS has been shown to reduce oxygen and respirator pressure requirements and decrease the incidence of air leaks, death, and bronchopulmonary dysplasia. ${ }^{14}$ There is conflicting information, however, about the efficacy of dry artificial surfactant in RDS. ${ }^{24} 25$

Although lack of surfactant is the principal cause of RDS and supplementation of surfactant possibly results in immediate amelioration of respiratory failure, a 'drug' that supposedly stimulates synthesis of surfactant cannot have a similar effect, as it requires time before a change in endogenous synthesis, secretion, and accumulation of surfactant into the airways takes place. None the less, both exogenous natural surfactant ${ }^{14}$ and inositol reduced the severity of RDS, although the former had a more striking effect. Infants treated with inositol had fewer failures of indomethacin to close the patent ductus arteriosis compared with controls. It is difficult to conceive that all these effects were due to an increase in production of surfactant. Although there are no other explanations at present, it is possible that systems other than the surfactant depend on dietary inositol too.

Inositol-phosphoinositide pair serves as a 'tertiary' messenger of various functions associated with the cell membrane-for instance, secretion of many hormones (glucocorticoids, thyrotrophin releasing hormone, insulin, angiotensin, acetylcholine, and others), local factors (epidermal growth factor), transmission of nerve impulse, or function of white cells. ${ }^{426}$ The evidence that inositol is important in reproduction and early development has been challenged ${ }^{8}$ and in view of the ubiquitous synthesis and active intracellular transport of this sugar it has been considered that the availability of inositol is not rate limiting in the transmitter functions concerned. This concept may not always be true because-for example, in experimental diabetic neuropathy-inositol supplementation restores neuronal inositol concentration and improves the abnormal peripheral nerve conduction velocity. ${ }^{27}$

Inositol is highly compartmentalised. Although a high affinity, sodium requiring active inositol transport is present in any tissue, the availability of inositol in a specific intracellular site may depend on a variety of factors, such as active inositol uptake, endogenous synthesis, permeability, and concentration gradient across the membrane. These determinants additionally change during perinatal development ${ }^{21}$ or during disease. ${ }^{27}$ It is therefore conceivable that phosphoinositide mediated functions critically depend on the availability of inositol.

The present data, showing evidence of the beneficial effect of inositol in RDS, is still preliminary. Several important questions remain. Only small preterm infants with RDS were treated. The beneficial effect was evident among those with gestational ages less than 31 weeks and weighing less than $1500 \mathrm{~g}$. Newborns with renal failure were not treated as in uraemia the lack of renal inositol secretion and catabolism results in hyperinositolaemia. ${ }^{28}$ The dose, duration of treatment, and other pharmacodynamic aspects of inositol remain unclear, and the possibility that it causes side effects has not been excluded either. Long term follow up of the infants is in progress. Nevertheless, the present results support the concept that some substrates have specific roles in differentiation and raise a question whether immature newborn infants or some high risk fetuses need an adequate supply of a wider range of nutrients than considered necessary at present.

This study was supported by the Finnish Academy, the Sigrid Juselius Foundation, and the Foundation for Pediatric Research in Finland. We are grateful to the Department of Pharmacy, University Central Hospital, Helsinki, for preparing and testing the sugar solutions used in the present trial. We acknowledge the help of Dr E-M Tolppanen in statistical analysis.

\section{References}

1 Lewin LM, Melmed S, Passwell JH, et al. Myo-inositol in human neonates: serum concentrations and renal handling. Pediatr Res 1978;12:3-8.

2 Bleasdale JE, Maberry MC, Quirk JG. Myo-inositol homeostasis in fetal rabbit lung. Biochem $J$ 1982;206:43-52.

${ }^{3}$ Hallman M, Saugstad OD, Porreco RP, Epstein BL, Gluck L. Role of myo-inositol in regulation of surfactant phosphatidylglycerol and phosphatidylinositol. Early Hum Dev 1985; 10:245-54. 
${ }^{4}$ Michell RH. Inositol phospholipids and cell surface receptor function. Biochim Biophys Acta 1975;415:81-147.

5 Woolley DW. Identification of mouse alopecia factor. $J$ Biol Chem 1941;139:29-34.

${ }^{6}$ Chu SW, Hegsted DM. Myo-inositol deficiency in gerbils: changes in phospholipid composition of intestinal microsomes. J Nutr 1980;110:1217-23.

7 Burton LE, Wells WW. Myo-inositol deficiency, studies on the mechanism of lactation-dependent fatty liver formation on the rat. J Nutr 1979:109:1483-95.

${ }^{8}$ Holub BJ. The nutritional significance, metabolism, and function of myo-inositol and phosphatidylinositol in health and disease. Adv Nutr Res 1982;4:107-41.

${ }^{9}$ Hallman M. Effect of extracellular myo-inositol on surfactant phospholipid synthesis in the fetal rabbit lung. Biochim Biophys Acta 1984;795:67-78.

${ }^{10}$ Bromberger P, Hallman M. Myoinositol in small preterm infants relationship between intake and serum concentration. Journal of Pediatric Gastroenterology and Nutrition 1986;5:455.

$"$ Edwards DK, Hilton SvW, Merritt TA, Hallman M, Mannino F, Boynton BR. Respiratory distress syndrome treated with human surfactant: radiographic findings. Radiology 1985; 157:329-34.

12 Hallman M, Teramo K. Measurement of the lecithin sphingomyelin ratio and phosphatidylglycerol in the amniotic fluid: an accurate method for the evaluation of fetal lung maturity. Br J Obstet Gynaecol 1981;88:806-13.

13 Dillard R. Mean airway pressure calculation. J Pediatr 1980;97:506.

14 Hallman M, Merritt TA, Järvenpää A-L, et al. Exogenous human surfactant for treatment of severe respiratory distress syndrome: a randomized prospective clinical trial. J Pediatr 1985;106:963-9.

15 Northway WH, Rosan RC, Porter D. Pulmonary disease following respirator therapy of hyaline-membrane disease. Bronchopulmonary dysplasia. N Engl J Med 1967;276:357-68.

16 Papile L, Burstein J, Burstein R, Koffler H. Incidence and evolution of subependymal and intraventricular hemorrhage: a study of infants with birth weight less than 1500 grams. J Pediatr 1978;92:529-34.
17 Pocock SJ. Clinical trials. New York: John Wiley, 1983:123-41.

${ }^{18}$ Liggins GC, Howie RN. A controlled trial of antepartum glucocorticoid treatment for prevention of the respiratory distress syndrome in premature infants. Pediatrics 1972;50: 515-25.

${ }^{19}$ Beppu OS, Clements JA, Goerke J. Phosphatidylglyceroldeficient lung surfactant has normal properties. J Appl Physiol 1983:55:496-502.

20) Hallman M, Enhorning G, Possmayer F. Composition and surface activity of normal and phosphatidylglycerol-deficient lung surfactant. Pediatr Res 1985;19:286-92.

21 Hallman M, Slivka S, Wozniak P, Sills J. Perinatal development of myoinositol uptake into lung cells: surfactant phosphatidylglycerol and phosphatidylinositol synthesis in the rabbit. Pediatr Res 1986;20:179-85.

22 Ogasa K, Kuboyama M, Kiyosawa I, Suzuki K, Itok M. The content of free and bound inositol in human and cow's milk. J Nutr Sci Vitaminol (Tokyo) 1975;21:129-35.

${ }^{23}$ Baden M, Bauer CR, Colle E, Kein G, Taeusch HW, Stern LA. A controlled trial of hydrocortisone therapy in infants with respiratory distress syndrome. Pediatrics 1972;50:526-34.

${ }^{24}$ Morley CJ, Bangham AD, Miller N, Davis JA. Dry artificial lung surfactant and its effect on very premature babies. Lancet $1981 ; i: 64-8$.

${ }^{25}$ Wilkinson A, Jenkins P, Jeffrey J. Two controlled trials of dry artificial surfactant: early effects and later outcome in babies with surfactant deficiency. Lancet 1985;ii:287-91.

${ }^{26}$ Farese RV. Phosphoinositide metabolism and hormone action. Endocr Rev 1983;4:78-95.

27 Green DA, De Jesus PV Jr, Winegrad Al. Effects of insulin and dietary myo-inositol on impaired peripheral nerve conduction velocity in acute streptozotocin diabetes. J Clin Invest 1975;55:1326-36.

${ }^{28}$ Blumberg A, Esslen E, Burgi W. Myo-inositol-a uremic neurotoxin? Nephron 1978;21:186-91.

Correspondence to Dr M Hallman, Children's Hospital, University of Helsinki, Stenbäckinkatu 11, 00290 Helsinki, Finland.

Received 1 July 1986 